\title{
An approximate method for lateral stability analysis of wall-frame buildings including shear deformations of walls
}

\author{
KANAT BURAK BOZDOGAN* and DUYGU OZTURK \\ Department of Civil Engineering, Ege University, İzmir, 35040 Turkey \\ e-mail: kanat.burak.bozdogan@ege.edu.tr
}

MS received 10 September 2008; revised 21 October 2009; accepted 16 November 2009

\begin{abstract}
This study presents an approximate method based on the continuum approach and transfer matrix method for lateral stability analysis of buildings. In this method, the whole structure is idealized as an equivalent sandwich beam which includes all deformations. The effect of shear deformations of walls has been taken into consideration and incorporated in the formulation of the governing equations. Initially the stability differential equation of this equivalent sandwich beam is presented, and then shape functions for each storey is obtained by the solution of the differential equations. By using boundary conditions and stability storey transfer matrices obtained by shape functions, system buckling load can be calculated. To verify the presented method, four numerical examples have been solved. The results of the samples demonstrate the agreement between the presented method and the other methods given in the literature.
\end{abstract}

Keywords. Stability; transfer matrix; continuum model; shear deformation.

\section{Introduction}

The stability analysis of a building can and should be assessed by looking at its individual elements as well as examining its stability as a whole (Zalka 2002). A number of methods including finite element method have been developed for stability analysis of the buildings. In the literature there are numerous studies (Rutenberg et al 1988; Syngellakis \& Kameshki 1994; Aristizabal-Ochoa 1997; Aristizabal-Ochoa 2002; Hoenderkamp 2002; Zalka 2002; Aristizabal-Ochoa 2003; Potzta \& Kollar 2003; Zalka 2003; Girgin et al 2006; Kaveh \& Salimbahrami 2006; Mageirou \& Gantes 2006; Tong \& Ji 2007; Gomes et al 2007; Girgin \& Ozmen 2007; Xu \& Wang 2007) concerning the stability analysis.

Rutenberg (1988) proposed a simple approximate lower bound formula for the gravity buckling loads of coupled shear-wall structures using continuous medium assumption. Hoenderkamp (2002) on the other hand, presented a simplified hand method for the calculation of the overall critical load of planar lateral resisting structures commonly used to provide stability in tall buildings. Zalka (2002) derived simplified analytical expressions for

${ }^{*}$ For correspondence 
the stability of wall-frame buildings. It has been assumed that the structures are regular (i.e. their characteristics do not vary over the height). Aristazabal Ochoa's papers (Aristazabal Ochoa 1997, 2002, 2003), storey-buckling approach was used for the stability of the unbraced frame. Also, Potzta \& Kollar (2003) developed a hand method for stability and dynamic analysis of regular buildings. In their paper, the stiffened building structure was replaced by a sandwich beam. Additionally, Girgin \& Ozmen (2007) proposed a simplified procedure for determining buckling loads of three-dimensional framed structures.

In this study, an approximate method based on continuum system model and transfer matrix approach has been suggested for the lateral stability analysis of the buildings. The effect of shear deformations of walls has been taken into consideration and incorporated in the formulation of the governing equations. The following assumptions are made in this study; the behaviour of the material is linear elastic, the floor slabs of the building have great in-plane and small out-of-plane stiffness, the vertical load acts on storey level and the critical loads of the structures define the bifurcation point.

\section{Analyses}

\subsection{Transfer matrix method}

In various engineering problems, as the number of constants to be determined by the use of boundary conditions increases, the computations become more tedious and the possibility of making errors also increases. For this reason, ways of reducing the number of constants to a minimum are sought. The transfer matrix method makes this possible. The main principle of this methodology, which is applied to problems with one variable, is to convert boundary value problems into problems of initials values. Thus, new constants that may result from the use of intermediate condition are eliminated. Therefore, it is a method of expressing the equations in terms of the initial constants and it makes no distinction between the so called determinate and indeterminate problems of elastomechanics (Inan 1968). Transfer matrix method is an efficient and easily computerized method which also provides a fast and practical solution since the dimension of the matrix for elements and system never changes (Pestel \& Leckie 1963).

\subsection{Physical model}

High rise buildings demonstrate neither Timoshenko beam behaviour nor Euler-Bernouilli beam behaviour under horizontal loads (Potzta \& Kollar 2003). The behaviour of the high rise buildings may be presented by the sandwich beam which consists of two Timoshenko cantilever beams ( $A$ and $B$ ) and demonstrates both of the mentioned behaviours (figure 1).

The flexural rigidity $(E I)$ of beam $A$ is the sum of the flexural rigidities of shear walls and columns. The shear rigidity $\left(G A_{w}\right)$ of beam $A$ is the sum of the shear rigidities of walls. Meanwhile, the shear rigidity $(G A)_{f}$ of the beam $B$ is equal to the sum of shear rigidities of frames and sum of shear rigidities of the connecting beams. The global flexural rigidity $(D)$ of beam $B$ can be calculated with the help of axial deformation of shear walls and columns.

\subsection{Stability transfer matrices}

Stability equations for high rise buildings under the horizontal loads are shown in the equations (1)-(3), (Lee et al 2008). Equation (1) presents the distributed load for $i$-th storey.

$$
\frac{d}{d z_{i}}\left[(G A)_{w i}\left(\frac{d y_{i}}{d z_{i}}-\psi_{w i}\right)\right]+\frac{d}{d z_{i}}\left[(G A)_{f i}\left(\frac{d y_{i}}{d z_{i}}-\psi_{f i}\right)\right]-N_{i} \frac{d^{2} y_{i}}{d z_{i}^{2}}=0 .
$$




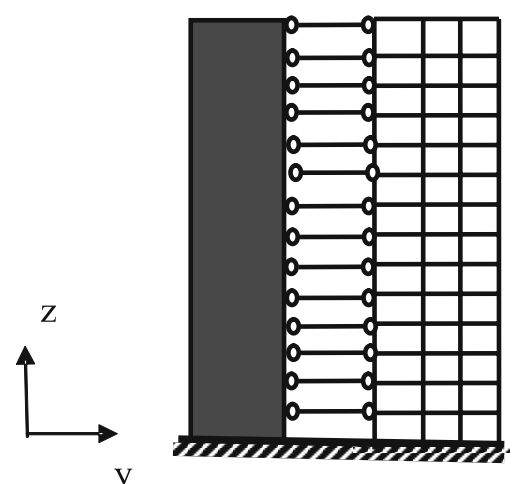

$\mathrm{y}$

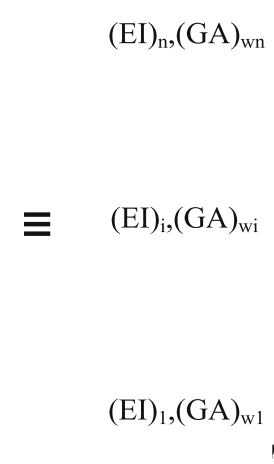

(A)

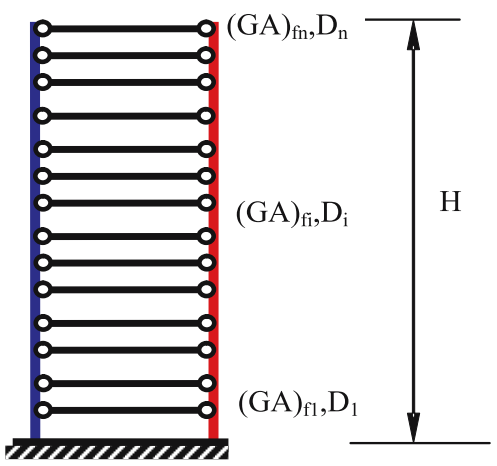

(B)

Figure 1. Physical model of equivalent sandwich beam.

Equations (2) and (3) present the shear force equilibrium for beam $A$ and beam $B$, respectively, which are shown in figure 1.

$$
\begin{aligned}
& \frac{d}{d z_{i}}\left[(E I)_{w i} \frac{d \psi_{w i}}{d z_{i}}\right]+(G A)_{w i}\left(\frac{d y_{i}}{d z_{i}}-\psi_{w i}\right)=0 \\
& \frac{d}{d z_{i}}\left[(D)_{i} \frac{d \psi_{f i}}{d z_{i}}\right]+(G A)_{f i}\left(\frac{d y_{i}}{d z_{i}}-\psi_{f i}\right)=0 .
\end{aligned}
$$

In the above equations, $y_{i}$ are the total displacement functions; $z_{i}$ are the vertical axis of $i$-th storey; $N_{i}$ are the axial forces; $\psi_{w i}$ denote rotations of a transverse normal of shear wall; $\psi_{f i}$ denote rotations of a transverse normal of frame; $E I_{i}$ are the total bending rigidities of shear walls and columns; and $D_{i}$ are the global bending rigidities of frame and can be calculated using the equation below,

$$
D_{i}=\sum_{j=1}^{n} E A_{j} r_{j}^{2}
$$

where $A_{j}$ are the cross sectional areas of $j$-th shear wall/column; $n$ is the number of columns; and $r$ are the distances of the $j$-th shear wall/column from the center of the cross sections. $\left(G A_{w i}\right)$ are the equivalent shear rigidities of walls and $\left(G A_{f i}\right)$ are the equivalent shear rigidities of the framework. For frame elements which consist of $n$ columns and $n-1$ beams, $G A_{f i}$ can be calculated by equation (5) (Murashev et al 1972; Stafford Smith \& Crowe 1986).

$$
G A_{f i}=\frac{12 E}{\left.h_{i}\left[1 / \sum_{1}^{n} I_{c} / h_{i}+1 / \sum_{1}^{n-1} I_{g} / l\right)\right]} .
$$

Here, $\sum I_{c} / h_{i}$ represents the sum of moments of inertia of the columns per unit height in $i$-th storey of frame $j$, and $\sum I_{g} / l$ represents the sum of moments of inertia of each beam per unit span across one floor of frame $j$. 


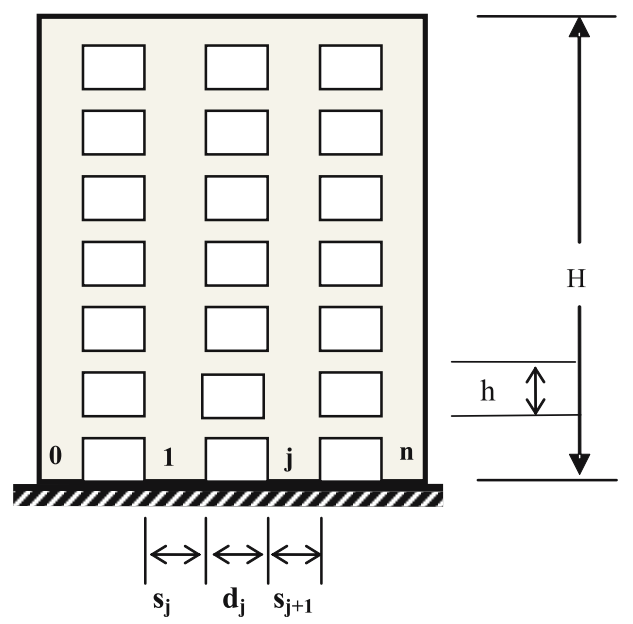

Figure 2. Coupled shear wall.

For coupled shear wall which consists of $n$ walls and $n-1$ connecting beams, ignoring the wall effects $G A_{f i}$ can be calculated by equation (6) (Rosman 1964; Murashev et al 1972),

$$
G A_{f i}=\sum_{j=1}^{n-1} \frac{6 E I_{b j}\left[\left(d_{j}+s_{j}\right)^{2}+\left(d_{j}+s_{j+1}\right)^{2}\right]}{d_{j}^{3}\left(h_{i}+\frac{12 \rho E I_{b j}}{G A_{b j} d_{j}^{2}}\right)},
$$

where, $h_{i}$ are heights of storeys; $d_{j}$ are the clear span lengths of coupling beam; $s_{j}$ are the wall lengths (figure 2); $E I_{b j}$ and $G A_{b j}$ represent the flexural rigidities and the shear rigidities of connecting beams, respectively. $\rho$ is the constant depending on the shape of cross-sections of the beams ( $\rho=1.2$ for rectangular cross-sections).

With the solution of the equations (1), (2) and (3), total displacement functions $\left(y_{i}\right)$ and rotation angles $\left(\psi_{w i}, \psi_{f i}\right)$ can be obtained as follows:

$$
\begin{aligned}
& y_{i}\left(z_{i}\right)=c_{1}+c_{2} z_{i}+c_{3} \cosh \left(a_{i} z_{i}\right)+c_{4} \sinh \left(a_{i} z_{i}\right)+c_{5} \cos \left(b_{i} z_{i}\right)+c_{6} \sin \left(b_{i} z_{i}\right), \\
& \psi_{w i}\left(z_{i}\right)=c_{2}+R_{w i} c_{3} \sinh \left(a_{i} z_{i}\right)+R_{w i} c_{4} \cosh \left(a_{i} z_{i}\right)-F_{w i} c_{5} \sin \left(b_{i} z_{i}\right)+F_{w i} c_{6} \cos \left(b_{i} z_{i}\right), \\
& \psi_{f i}\left(z_{i}\right)=c_{2}+R_{f i} c_{3} \sinh \left(a_{i} z_{i}\right)+R_{f i} c_{4} \cosh \left(a_{i} z_{i}\right)-F_{f i} c_{5} \sin \left(b_{i} z_{i}\right)+F_{f i} c_{6} \cos \left(b_{i} z_{i}\right),
\end{aligned}
$$

where $c_{1}, c_{2}, c_{3}, c_{4}, c_{5}, c_{6}$ are integral constants; $a_{i}$ and $b_{i}$ are the representative of the long terms of equations which can be calculated by using formulas given below.

$$
\begin{aligned}
& a_{i}=\sqrt{\frac{g_{i} / e_{i}+\sqrt{\left(g_{i} / e_{i}\right)^{2}+4 N_{i} G A_{w i} G A_{f i} / e_{i}}}{2}} \\
& b_{i}=\sqrt{\frac{-g_{i} / e_{i}+\sqrt{\left(g_{i} / e_{i}\right)^{2}+4 N_{i} G A_{w i} G A_{f i} / e_{i}}}{2}},
\end{aligned}
$$


$e_{i}, g_{i}$ can be calculated from equations (12) and (13) as shown below:

$$
\begin{aligned}
e_{i} & =E I_{w i} D_{i}\left(G A_{w i}+G A_{f i}-N_{i}\right) \\
g_{i} & =\left[G A_{w i} G A_{f i}\left(D_{i}+E I_{i}\right)-N_{i}\left(G A_{f} E I_{w}+G A_{w} D_{i}\right)\right] .
\end{aligned}
$$

$R_{w i}, R_{f i}, F_{w i}$ and $F_{f i}$ can be calculated from equations (14), (15), (16) and (17) as shown below:

$$
\begin{aligned}
R_{w i} & =\frac{(G A)_{w i} a_{i}}{\left[(G A)_{w i}-a_{i}^{2}(E I)_{w i}\right]} \\
R_{f i} & =\frac{(G A)_{f i} a_{i}}{\left[(G A)_{f i}-a_{i}^{2}(D)_{i}\right]} \\
F_{w i} & =\frac{(G A)_{w i} b_{i}}{\left[(G A)_{w i}+b_{i}^{2}(E I)_{w i}\right]} \\
F_{f i} & =\frac{(G A)_{f i} b_{i}}{\left[(G A)_{f i}-b_{i}^{2}(D)_{i}\right]} .
\end{aligned}
$$

With the help of equations (7), (8) and (9), bending moment of the shear wall and bending moment of the frames due to axial deformation along with the total shear force can be obtained as follows:

$$
\begin{aligned}
M_{w i}\left(z_{i}\right)= & (E I)_{w i} \psi_{w i}^{l}=(E I)_{w i}\left[a_{i} R_{w i} c_{3} \cosh \left(a_{i} z_{i}\right)+a_{i} R_{w i} c_{4} \sinh \left(a_{i} z_{i}\right)\right. \\
& \left.-b_{i} F_{w i} c_{5} \cos \left(b_{i} z_{i}\right)-b_{i} F_{w i} c_{6} \sin \left(b_{i} z_{i}\right)\right] \\
M_{f i}\left(z_{i}\right)= & D_{i} \psi_{f i}^{\prime}=D_{i}\left[a_{i} R_{f i} c_{3} \cosh \left(a_{i} z_{i}\right)+a_{i} R_{f i} c_{4} \sinh \left(a_{i} z_{i}\right)\right. \\
& \left.-b_{i} F_{f i} c_{5} \cos \left(b_{i} z_{i}\right)-b_{i} F_{f i} c_{6} \sin \left(b_{i} z_{i}\right)\right] \\
V_{i}\left(z_{i}\right)= & \left(E I_{w i}\right) \frac{d^{2} \psi_{w i}}{d z_{i}^{2}}+D_{i} \frac{d^{2} \psi_{f i}}{d z_{i}^{2}}+N_{i} \frac{d y_{i}}{d z_{i}} \\
= & c_{2} N_{i}+c_{3}\left[E I_{i} R_{w i} a_{i}^{2} \sinh \left(a_{i} z_{i}\right)+D_{i} R_{f i} a_{i}^{2} \sinh \left(a_{i} z_{i}\right)+N_{i} a_{i} \sinh \left(a_{i} z_{i}\right)\right] \\
& +c_{4}\left[E I_{i} R_{w i} a_{i}^{2} \cosh \left(a_{i} z_{i}\right)+D_{i} R_{f i} a_{i}^{2} \cosh \left(a_{i} z_{i}\right)+N_{i} a_{i} \cosh \left(a_{i} z_{i}\right)\right] \\
& +c_{5}\left[E I_{i} F_{w i} b_{i}^{2} \sin \left(b_{i} z_{i}\right)+D_{i} F_{f i} b_{i}^{2} \sin \left(b_{i} z_{i}\right)-N_{i} b_{i} \sin \left(b_{i} z_{i}\right)\right] \\
& +c_{6}\left[-E I_{i} F_{w i} b_{i}^{2} \cos \left(b_{i} z_{i}\right)-D_{i} F_{f i} b_{i}^{2} \cos \left(b_{i} z_{i}\right)+N_{i} b_{i} \cos \left(b_{i} z_{i}\right)\right]
\end{aligned}
$$

Equation (21) shows the matrix form of equations (7), (8), (9), (18), (19) and (20):

$$
\left[\begin{array}{c}
y_{i}\left(z_{i}\right) \\
\psi_{w i}\left(z_{i}\right) \\
\psi_{f i}\left(z_{i}\right) \\
M_{w i}\left(z_{i}\right) \\
M_{f i}\left(z_{i}\right) \\
V_{i}\left(z_{i}\right)
\end{array}\right]=B_{i}\left(z_{i}\right)\left[\begin{array}{c}
c_{1} \\
c_{2} \\
c_{3} \\
c_{4} \\
c_{5} \\
c_{6}
\end{array}\right] .
$$


At the initial point of the storey for $z_{i}=0$, equation (21) can be written as:

$$
\left[\begin{array}{c}
y_{i}(0) \\
\psi_{w i}(0) \\
\psi_{f i}(0) \\
M_{w i}(0) \\
M_{f i}(0) \\
V_{i}(0)
\end{array}\right]=B_{i}(0)\left[\begin{array}{c}
c_{1} \\
c_{2} \\
c_{3} \\
c_{4} \\
c_{5} \\
c_{6}
\end{array}\right]
$$

The vector in right-hand side of equation (22) can be shown as follows:

$$
c=\left[\begin{array}{llllll}
c_{1} & c_{2} & c_{3} & c_{4} & c_{5} & c_{6}
\end{array}\right]^{t} .
$$

When vector $c$ is solved from equation (22) and is substituted to the equations (21), then equation (24) is obtained.

$$
\left[\begin{array}{c}
y_{i}(z) \\
\psi_{w i}(z) \\
\psi_{f i}(z) \\
M_{w i}(z) \\
M_{f i}(z) \\
V_{i}(z)
\end{array}\right]=B_{i}(z) B_{i}(0)^{-1}\left[\begin{array}{c}
y_{i}(0) \\
\psi_{w i}(0) \\
\psi_{f i}(0) \\
M_{w i}(0) \\
M_{f i}(0) \\
V_{i}(0)
\end{array}\right]
$$

where $S_{i}=B_{i}\left(h_{i}\right) B_{i}(0)^{-1}$ is the storey transfer matrix for $z_{i}=h_{i}$.

\section{Determination of critical buckling load}

The storey stability transfer matrices in equation (24) can be used for stability analysis of high rise buildings.

The displacements and internal forces relationship between the base and the top of the structure can be found as follows:

$$
\left[\begin{array}{c}
y_{\text {top }} \\
\psi_{\text {wtop }} \\
\psi_{\text {ftop }} \\
M_{\text {wtop }} \\
M_{\text {ftop }} \\
V_{\text {top }}
\end{array}\right]=S_{n} S_{(n-1)} \ldots \ldots \ldots S_{1}\left[\begin{array}{c}
y_{\text {base }} \\
\psi_{\text {wbase }} \\
\psi_{\text {fbase }} \\
M_{\text {wbase }} \\
M_{\text {fbase }} \\
V_{\text {base }}
\end{array}\right] .
$$

The boundary conditions of the shear wall-frame system are:
1) $y_{\text {base }}=0$,
2) $\psi_{\text {wbase }}=0$,
3) $\psi_{\text {fbase }}=0$,
4) $\left.M_{\text {wtop }}=0,5\right) M_{\text {ftop }}=0$,
6) $V_{\text {top }}=0$.

When the boundary conditions are considered in equation (25), for non-trivial solution of system transfer matrix $\left(S=S_{n} S_{n-1} S_{n-2} \ldots \ldots \ldots S_{1}\right)$ equation (26) is obtained:

$$
f=\left[\begin{array}{lll}
s_{44} & s_{45} & s_{46} \\
s_{54} & s_{55} & s_{56} \\
s_{64} & s_{65} & s_{66}
\end{array}\right] .
$$

The values of $N$ which set the determinant to zero are the critical buckling load of the building. 


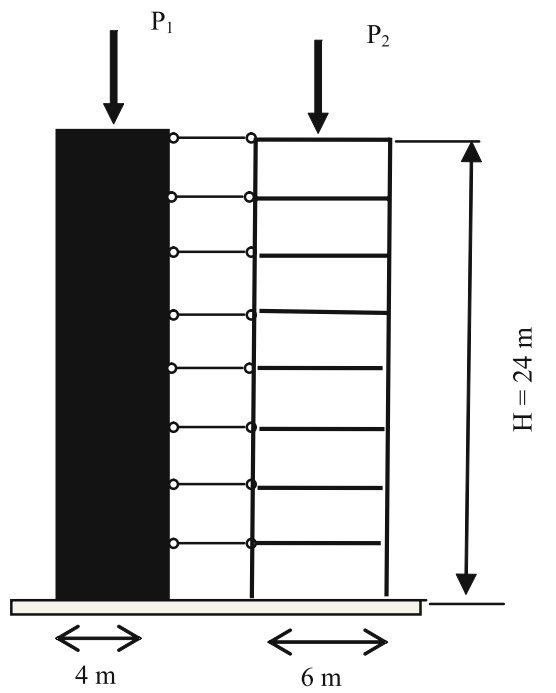

Figure 3. Wall-frame structure.

\section{Procedure of computation}

The step-by-step procedure of the computation of transfer matrix method is presented below:

(i) Calculation of the structural properties $\left(G A_{i}, E I_{i}, D_{i}, N_{i}\right)$ of each storey using equations (4), (5) and (6).

(ii) Computation of storey transfer matrices as determined in equation (24) for each storey using the structural properties obtained in step 1.

(iii) Computation of system stability transfer matrix as in equation (25) with the help of the storey transfer matrices.

(iv) Applying the boundary conditions in equation (25) and obtaining the non-trivial equation (equation 26).

(v) Determination of the buckling load by using numerical method.

\section{Numerical examples}

In this part of the study, to verify the presented method, four numerical examples have been solved by a program written in MATLAB. The results have been compared with those given in the literature.

Example 1. Consider the wall-frame dual system which is vertically loaded at top as shown in figure 3. The total height of building is $24 \mathrm{~m}$. The equivalent rigidities of the shear wall are $E I_{i}=32 * 10^{6} \mathrm{kNm}^{2}, G A_{w i}=10 \cdot 3 * 10^{6} \mathrm{kN}$, and the equivalent rigidities of the frames are: $D_{i}=39.2 * 10^{6} \mathrm{kNm}^{2}, G A_{f i}=24.5 * 10^{6} \mathrm{kN}$. The critical buckling load factor has been calculated with the presented method and has been compared (table 1) with that found in the literature (Gengshu et al 2008).

To investigate the shear deformation effects on the critical buckling load, the structure has been analysed with, and without, considering the shear deformation effects. Besides, the same structure with different heights has been investigated (tables 2 and table 3 ) to present the shear 
Table 1. Comparison of critical buckling load factor in example 1.

\begin{tabular}{lcc}
\hline & Gengshu et al (2008) & Presented method \\
\hline Critical load factor & $302053.931 \mathrm{kN}$ & $302050 \mathrm{kN}$ \\
\hline
\end{tabular}

Table 2. Comparison of shear effect in the structure with different number of storeys $(l=4 \mathrm{~m})$.

\begin{tabular}{lcc}
\hline Total storey & Without shear deformation & With shear deformation \\
\hline 2 & $4614500 \mathrm{kN}$ & $4229400 \mathrm{kN}$ \\
4 & $1202100 \mathrm{kN}$ & $1174400 \mathrm{kN}$ \\
6 & $538630 \mathrm{kN}$ & $532990 \mathrm{kN}$ \\
8 & $303850 \mathrm{kN}$ & $302050 \mathrm{kN}$ \\
\hline
\end{tabular}

Table 3. Comparison of shear effect in the structure with different number of storeys $(l=6 \mathrm{~m})$.

\begin{tabular}{lcc}
\hline Total storey & Without shear deformation & With shear deformation \\
\hline 2 & $9823400 \mathrm{kN}$ & $7425700 \mathrm{kN}$ \\
4 & $2510200 \mathrm{kN}$ & $2228300 \mathrm{kN}$ \\
6 & $1117400 \mathrm{kN}$ & $1075800 \mathrm{kN}$ \\
8 & $629410 \mathrm{kN}$ & $615960 \mathrm{kN}$ \\
\hline
\end{tabular}

deformation effects. Further, the length of the shear wall $(l)$ is taken as $4 \mathrm{~m}$ (table 2) and $6 \mathrm{~m}$ (table 3).

As can be seen from the tables 2 and 3 , the shear deformation effect becomes more important when the length of the shear wall is increased and the height of the structure is decreased.

Example 2. The frame structure with two spans eleven storeys in figure 4 has been considered for Example 2. The section properties of columns and heights of the storeys are given in table 4. All girders have the same cross section, and the modulus of elasticity of the structure is $E=25000 \mathrm{MN} / \mathrm{m}^{2}$. The equivalent rigidities of each storey have been calculated and are presented in table 5 .

The critical buckling load factor has been calculated using the present method and compared with the obtained results of Syngellakis \& Kameshki 1994 (table 6).

Example 3. In this example, the coupled shear wall structure as in figure 5 has been analysed by the proposed method. The shear walls have $4 \mathrm{~m}$ length and $0.4 \mathrm{~m}$ width. The height of connecting beams between the shear walls are $0.8 \mathrm{~m}$ and the thickness of the beams are $0.4 \mathrm{~m}$. The modulus of elasticity and the Poisson's ratio of the system are equal to $20 \mathrm{kN} / \mathrm{mm}^{2}$ and $0 \cdot 25$, respectively.

Equivalent rigidities have been calculated and the storey transfer matrices have been obtained by using equation (24). The system stability matrix has been obtained by using equation (25). Finally, by applying the boundary conditions, equation (26) is gained and the critical buckling load is found. It has been compared with the result found by SAP 2000 (table 7). 


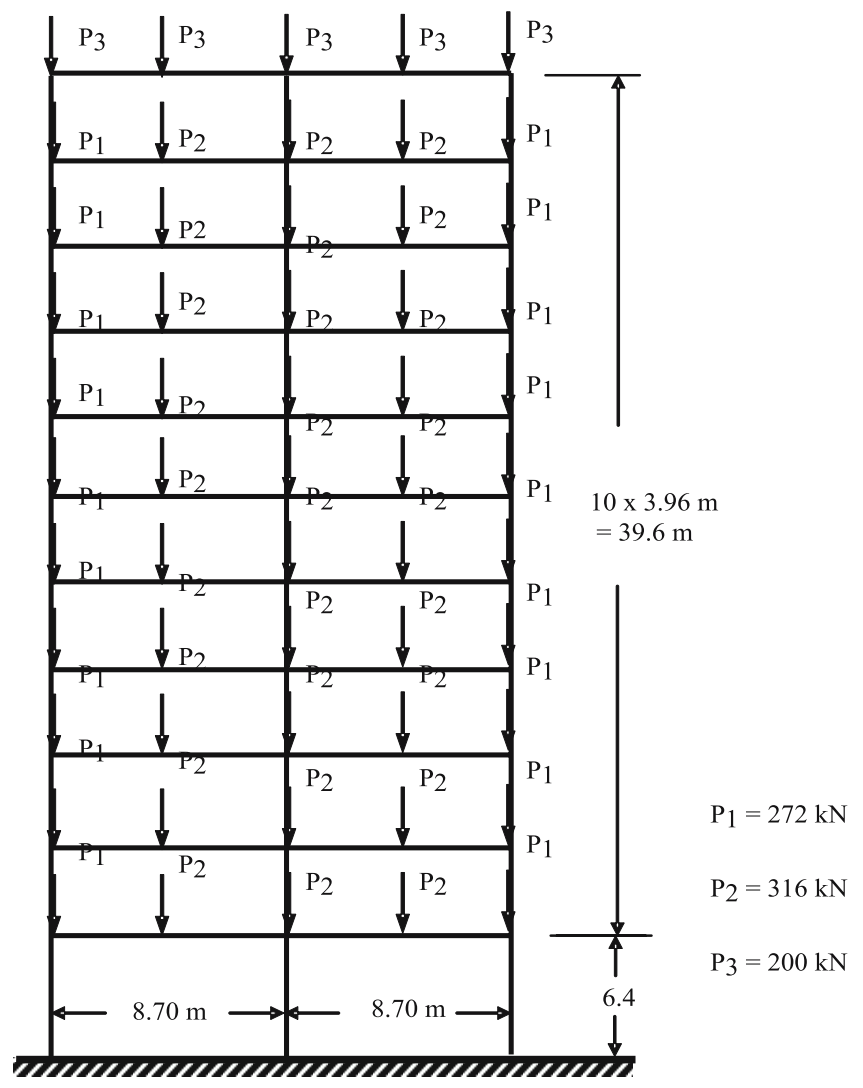

Figure 4. Two bay frame (Example 1).

Example 4. A 15-storey tube in tube structure has been analysed as an example. The plan of structure is shown in figure 6 . The modulus of elasticity of the structure is $E=2.1 *$ $10^{6} \mathrm{Mp} / \mathrm{m}^{2}$, the height of each storey is $h=3.20 \mathrm{~m}$, and the total height of the building is $H=48 \mathrm{~m}$. The cross-sections of the rectangular columns and lintels of the outer tube are $0.35 \mathrm{~m} * 0.55 \mathrm{~m}$ and $0.30 \mathrm{~m} * 0.80 \mathrm{~m}$, respectively. The thickness of shear wall is $0.20 \mathrm{~m}$. The equivalent rigidities of each storey have been calculated by using equations (4), (5) and are presented in tables 8 and 9. The critical buckling loads have been calculated in the two directions by this method and compared with those found in the literature (Rosman 1974). The results are shown in table 10.

Table 4. Moment of inertia of columns in Example 2.

\begin{tabular}{lccc}
\hline Storey & Storey height & Exterior column & Interior column \\
\hline 1 & $6.4 \mathrm{~m}$ & $204370 \mathrm{~cm}^{4}$ & $250160 \mathrm{~cm}^{4}$ \\
2 & $3.96 \mathrm{~m}$ & $204370 \mathrm{~cm}^{4}$ & $250160 \mathrm{~cm}^{4}$ \\
$3-4$ & $3.96 \mathrm{~m}$ & $146929 \mathrm{~cm}^{4}$ & $183140 \mathrm{~cm}^{4}$ \\
$5-6$ & $3.96 \mathrm{~m}$ & $111130 \mathrm{~cm}^{4}$ & $146929 \mathrm{~cm}^{4}$ \\
$7-8$ & $3.96 \mathrm{~m}$ & $84079 \mathrm{~cm}^{4}$ & $146929 \mathrm{~cm}^{4}$ \\
$9-11$ & $3.96 \mathrm{~m}$ & $57024 \mathrm{~cm}^{4}$ & $84079 \mathrm{~cm}^{4}$
\end{tabular}


Table 5. Equivalent rigidities in Example 2.

\begin{tabular}{lcccc}
\hline Storey & $(E I)$ & $(G A)_{f i}$ & $D$ & $(G A)_{w}$ \\
\hline 1 & $135074 \cdot 5 \mathrm{kNm}^{2}$ & $5612.119 \mathrm{kN}$ & Infinite & Infinite \\
2 & $135074.5 \mathrm{kNm}^{2}$ & $9502.238 \mathrm{kN}$ & Infinite & Infinite \\
$3-4$ & $97785 \mathrm{kNm}^{2}$ & $9179.119 \mathrm{kN}$ & Infinite & Infinite \\
$5-6$ & $75684.048 \mathrm{kNm}^{2}$ & $8861.857 \mathrm{kN}$ & Infinite & Infinite \\
$7-8$ & $64592.57 \mathrm{kNm}^{2}$ & $8635.381 \mathrm{kN}$ & Infinite & Infinite \\
$9-11$ & $40616.36 \mathrm{kNm}^{2}$ & $7828.071 \mathrm{kN}$ & Infinite & Infinite \\
\hline
\end{tabular}

Table 6. Comparison of critical buckling load factor in Example 2.

\begin{tabular}{lcc}
\hline & Syngellakis \& Kameshki (1994) & Presented method \\
\hline Critical load factor & $7.7000 \mathrm{kN}$ & $7.8142 \mathrm{kN}$ \\
\hline
\end{tabular}

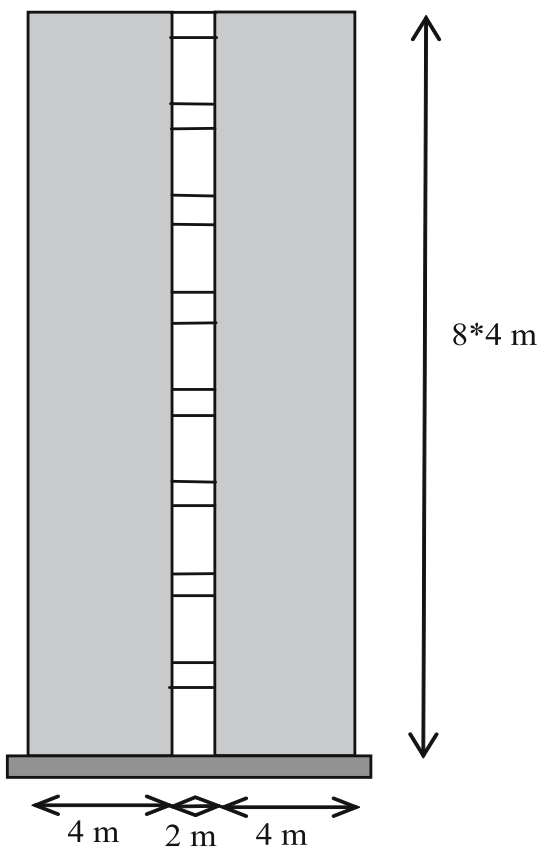

Figure 5. Coupled shear wall.

Table 7. Comparison of critical buckling load factor in Example 2.

Critical buckling load

\begin{tabular}{lc}
\hline SAP 2000 (Wide column) & Presented method \\
\hline $3103975 \cdot 345 \mathrm{kN}$ & $3302240 \mathrm{kN}$ \\
\hline
\end{tabular}



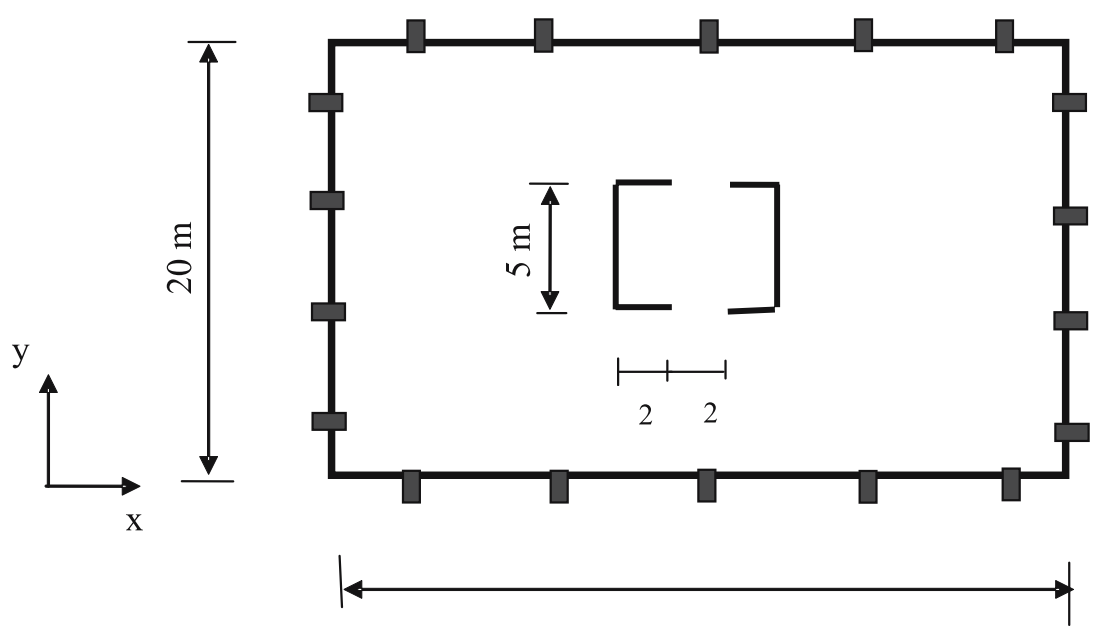

$$
25 \mathrm{~m}
$$

Figure 6. Tube in tube structure.

Table 8. Equivalent rigidities of the system in Example 4 in $x z$ plane.

\begin{tabular}{lcccr}
\hline Storey & $(G A)_{w i}$ & $(E I)_{w i}$ & $(G A)_{f i}$ & $(D)_{i}$ \\
\hline $1-15$ & infinite & $2.987 * 10^{6} \mathrm{Mpm}^{2}$ & $53140 \mathrm{Mp}$ & infinite \\
\hline
\end{tabular}

Table 9. Equivalent rigidities of the system in Example 4 in $y z$ plane.

\begin{tabular}{ccccc}
\hline Storey & $(G A)_{w i}$ & $(E I)_{w i}$ & $(G A)_{f i}$ & $(D)_{i}$ \\
\hline $1-15$ & infinite & $2.975 * 10^{7} \mathrm{Mpm}^{2}$ & $41868.182 \mathrm{Mp}$ & infinite
\end{tabular}

Table 10. Comparison of critical buckling load in Example 4.

\begin{tabular}{lccc}
\hline \multicolumn{3}{c}{ Critical buckling loads (Mp) } \\
\hline Direction & Rosman (1974) & Presented method & Difference (\%) \\
\hline$y$ & $1.044 * 10^{5}$ & $1.123 * 10^{5}$ & 7.57 \\
$z$ & $2.195 * 10^{5}$ & $2 \cdot 182 * 10^{5}$ & 0.59 \\
\hline
\end{tabular}

\section{Conclusions}

In this study, an approximate method based on the continuum approach and transfer matrix method for lateral stability analysis of buildings has been presented. In this method, the whole 
structure is idealized as an equivalent sandwich beam which includes all deformations. The effect of shear deformations of walls has been taken into consideration and incorporated in the formulation of the governing equations. Examples have shown that the results obtained from the proposed method are in good agreement with Finite Element Method and the analytical solution which has been developed by Rosman. The proposed method is not only simple and accurate enough to be used both at the concept design stage and for final analyses, but at the same time takes less computational time than the Finite Element Method.

\section{References}

Aristizabal-Ochoa J D 1997 Story stability of braced, partially braced and unbraced frames; Classical approach. ASCE J. Structural Eng. 123(6): 799-807

Aristizabal-Ochoa J D 2002 Classic buckling of three-dimensional multi-column systems under gravity loads. ASCE J. Eng. Mechanics 128(6): 613-624

Aristizabal-Ochoa J D 2003 Elastic stability and second-order analysis of three dimensional frames: Effects of column orientation. ASCE J. Eng. Mechanics 129(11): 1254-1267

Gengshu T, Pi Y L, Bradford A, Tin-Loi F 2008 Buckling and second order effects in dual shearflexural systems. ASCE J. Struct. Eng. 134(11): 1726-1732

Girgin K, Ozmen G, Orakdogen E 2006 Buckling lengths of irregular frame columns. J. Constructional Steel Res. 62: 605-613

Girgin K, Ozmen G 2007 Simplified procedure for determining buckling loads of three-dimensional framed structures. Eng. Struct. 29(9): 2344-2352

Gomes F C T, Providencia E, Costa P M, Rodrigues J P C, Neves I C 2007 Buckling length of a steel column for fire design. Eng. Struct. 29(10): 2497-2502

Hoenderkamp D C J 2002 Critical loads of lateral load resisting structures for tall buildings. The Structural Design of Tall Buildings 11: 221-232

Inan M 1968 The method of initial values and carry-over matrix in elastomechanics, Middle East Technical University, Publication No. 20, p. 130

Kaveh A, Salimbahrami B 2006 Buckling load of symmetric plane frames using canonical forms. Computers and Struct. 85: 1420-1430

Lee J, Bang M, Kim J Y 2008 An analytical model for high-rise wall-frame structures with outriggers. The Structural Design of Tall and Special Buildings 17(4): 839-851

Mageirou G E, Gantes C J 2006 Buckling strength of multi-story sway, non sway and partially sway frames with semi rigid connections. J. Constructional Res. 62: 893-905

Murashev V, Sigalov E, Baikov V 1972 Design of reinforced concrete structures (Moscow: Mir Publisher)

Pestel E, Leckie F 1963 Matrix methods in elastomechanics (USA: McGraw-Hill) p. 435

Potzta G, Kollar L P 2003 Analysis of building structures by replacement sandwich beams. Int. J. Solids and Structures 40: 535-553

Rosman R 1964 Approximate analysis of shear walls subject to lateral loads. Proceedings of the American Concrete Institute 61(6): 717-734

Rosman R 1974 Stability and dynamics of shear-wall frame structures. Building Science 9: 55-63

Rutenberg A, Levithian I, Decalo M 1988 Stability of shear-wall structures. ASCE J. Structural Division 114(3): 707-716

Stafford Smith B, Crowe E 1986 Estimating periods of vibration of tall buildings. J. Structural Division ASCE 112(5): 1005-1019

Syngellakis S, Kameshki E S 1994 Elastic critical loads for plane frames by transfer matrix method. ASCE J. Structural Division 120(4): 1140-1157

Tong G S, Ji Y 2007 Buckling of frames braced by flexural bracing. J. Constructional Steel Res. 63: $229-236$ 
Xu L, Wang X H 2007 Stability of multi-storey unbraced steel frames subjected to variable loading. J. Constructional Steel Res. 63(10): 1506-1514

Zalka K A 2002 Buckling analysis of buildings braced by frameworks, shear walls and cores. The Structural Design of Tall Buildings 11: 197-219

Zalka K A 2003 A hand method for predicting the stability of regular buildings, using frequency measurements. The Structural Design of Tall and Special Buildings 12: 273-281 